\title{
La comunicación vertical: un acercamiento a su problemática en las organizaciones
}

\author{
Francisco Alberto Vallejo Peña \\ Universidad de Málaga \\ favallejo@uma.es \\ Mariela Pardo Molina \\ SEUL (Service Européen des Étudiants Universitaires Latino-américains) \\ smsalapardo@skynet.be
}

\section{Resumen}

Considerando los tradicionales problemas de comunicación observados por la ciencia social en las organizaciones, hemos centrado - en este caso- nuestra atención en la comunicación vertical. Este tipo de comunicación presenta numerosas barreras y dificultades para la gestión de organizaciones, por la presencia de elementos latentes como la estratificación social y las diferencias de poder. Para profundizar en su análisis hemos seleccionado tres casos de empresas abordadas en estudios precedentes, que nos permitirán conocer como sus actores perciben la comunicación ascendente y descendente, asi como las disfunciones que ambas implican en el seno de sus organizaciones.

Palabras clave: comunicación organizacional, cultura organizacional, estructura de poder.

\begin{abstract}
Considering the traditional problems of communication identified by social science in organizations, we have centered -in this case-our attention on vertical communication. This type of communication presents several barriers and difficulties for the management of organizations, because of the presence of latent factors such as social stratification and power differences. For further analysis we selected three case-firms, addressed in previous studies, which will allow us to know how the actors perceive the upward and downward communication and dysfunctions involved within their organizations.
\end{abstract}

Key words: organizacional communication, organizacional culture, power structure. 


\section{Introducción}

«Eran las ocho de la tarde del viernes cuando aquel operario llegó a la puerta que precedía a la del despacho de su ocupado jefe y la encontró cerrada. En ese momento, soltó el aire que llevaba retenido en sus pulmones, permaneció estático ante la puerta, reflexionando durante unos instantes, y decidió que la ocasión merecía su insistencia. Golpeó fuerte con sus nudillos mientras pronunciaba el nombre de la secretaria de su superior. Tanto los reflejos de luz como el ruido que provocaba el movimiento de los pesados cajones de la mesa delataban que su jefe, acostumbrado a quedarse hasta altas horas de la noche más allá de su horario, continuaba trabajando. No obstante, prefirió cesar en su empeño, dio media vuelta y se dispuso a abandonar la planta, oscura y solitaria a aquellas horas. Al fin y al cabo, la repentina pérdida de líquido de aquella máquina que le había conducido a dar parte al jefe a deshoras provocaría problemas de organización y pérdidas económicas de las que otros implicados deberían responder el lunes». (Versión de un hecho real en una industria familiar de mediano tamaño.)

Este fragmento pretende recrear situaciones que cualquiera de nosotros ha vivido alguna vez en nuestras respectivas organizaciones. El mundo de la comunicación empresarial es extremadamente complejo y, por ello, es el núcleo de buena parte de nuestras preocupaciones en el trabajo. Aunque indagar en las causas de esta circunstancia conlleva un complejo estudio, debemos destacar dos cuestiones que están en el eje de nuestras preocupaciones: por una parte, la naturaleza disfuncional de la comunicación en las organizaciones, dada nuestra torpeza para transmitir y retener los mensajes, así como las dificultades para interpretar cuando carecemos de datos contextuales; por otra parte, la inevitable asociación entre el control de la comunicación y el poder de sus gestores, que condiciona su difusión, reserva y los tiempos de transmisión, de lo que resulta la ineludible manipulación.

El presente trabajo pretende reflexionar sobre algunas disfunciones y problemas clásicos en la comunicación vertical en organizaciones, especialmente la que se genera y distribuye en contextos en que, por naturaleza, existen fuertes diferencias de estatus, y por lo tanto de poder, que condicionan notablemente su gestión. Nuestra investigación parte de algunos conocidos planteamientos teóricos sobre comunicación procedentes de la sociología de las organizaciones y del ámbito de la organización de empresas, para añadir algunas observaciones procedentes de la realidad social y empresarial, de estudios de caso organizacionales realizados anteriormente, algunos de los cuales han sido vividos en primera persona por los autores de este estudio. En este sentido, nos hemos planteado la importancia y el interés de contar con casos y testimonios reales, procedentes de organizaciones tan dispares como una multinacional del transporte, una 
industria familiar de tamaño medio o un centro de formación, ya que interpretamos que el contrapunto que ofrecen organizaciones tan dispares en sus metas contribuye al enriquecimiento del análisis.

Partimos de la tesis de que la comunicación vertical es — por su naturaleza asimétrica-fuente de conflictos y disfunciones en las organizaciones, pero no tratamos de verificar una hipótesis que creemos que está sobradamente contrastada por la teoría orgánica. Nuestro objetivo es indagar en los motivos que hacen tan áspera esta comunicación, y, por tanto, digna de tratamiento excepcional. Aunque no pretendemos ofrecer las soluciones, esperamos introducir algunas aclaraciones que permitan al lector - auténtico conocedor de su contexto organizacional particular- reflexionar sobre las deficiencias de su caso, así como sobre las posibles mejoras.

Debemos resaltar que las relaciones verticales tienen, en un principio, naturaleza funcional. En primer lugar, se dan por consentimiento mutuo y, en segundo, garantizan el equilibrio y la supervivencia de la organización. Reforzando el primer argumento, Pithod (2001) sostiene: «El autoritarismo es una conducta social en la que se produce cierta distorsión no sólo en el ejercicio del poder, sino incluso en la percepción del mismo. El autoritarismo puede darse en el que ejerce el poder, pero también en el que está sometido a él». Tendremos entonces una asimétrica distribución del poder entre los grupos de la organización y, como consecuencia, una serie de comunicaciones verticales que vendrán marcadas por las directrices de los líderes. El segundo argumento - contribución al equilibrio y a la supervivencia de la organización - ha sido sustentado mayoritariamente, desde el diseño de Weber de su modelo burocrático hasta nuestros días. Incluso en las sociedades más democráticas e igualitarias, las jerarquías perviven en sus organizaciones. Sobre la gestión de grandes equipos humanos se ha teorizado mucho desde principios del siglo $\mathrm{xx}$, pero sin llegar a apartarnos demasiado del modelo piramidal.

\section{Objetivos y metodología}

De acuerdo con las anteriores consideraciones, hemos establecido los siguientes objetivos:

- Revisar el tratamiento que la teoría organizacional da a la comunicación vertical, a la que atribuye una problemática particular.

- Exponer algunos aspectos procedentes de estudios de caso realizados, en los que aparecen algunos problemas propios de la comunicación vertical. 
- Reflexionar sobre las causas que provocan algunos de los problemas y deficiencias frecuentes en nuestras organizaciones, vinculados a la comunicación vertical, para aportar algunas conclusiones al campo de estudio.

A tal efecto, presentamos a continuación la metodología utilizada, así como los antecedentes y referentes teóricos del problema. Posteriormente, indagaremos en los clásicos problemas organizacionales atribuidos a la comunicación, para entrar, finalmente, en los problemas especialmente atribuibles a la comunicación vertical y sus causas, sobre la que preguntamos en los distintos casos analizados.

Hemos emprendido un estudio cualitativo con la aplicación de técnicas como la observación directa, participante y la entrevista abierta, con objeto de analizar los discursos más relevantes sobre problemas en la comunicación vertical. Así mismo, se han recopilado informaciones del ámbito de la comunicación organizacional para contrastar las distintas fuentes teóricas y, posteriormente, cruzarlas con las notas obtenidas en nuestros trabajos de campo, realizados en organizaciones, vinculados a otros proyectos. El principal motivo que nos llevó a escoger el enfoque cualitativo es la necesidad de obtener una vasta profundidad en el discurso de nuestros informantes, tratando de alcanzar de esta manera aspectos reveladores de la naturaleza de los problemas, en la línea de los objetivos de nuestra investigación. El análisis de otras fuentes de carácter cuantitativo en estudios anteriores — Gil Estallo (2001a) o Vallejo Peña (2007) — nos sirvió para perfilar la caracterización general de la comunicación vertical.

Hemos tomado referencias de tres casos de la vida organizacional de compañías dedicadas a actividades de distinta naturaleza con objeto de contrastar observaciones realizadas en contextos diferentes. Se trata, en este caso, de una multinacional del transporte en España, un centro educativo privado en Argentina y una industria metalúrgica de tamaño medio en Bélgica. En estas experiencias se ha recopilado información de primera mano, si bien el comentario de estos casos se ha completado con otros ejemplos comentados extraídos de la literatura organizacional analizada, basados también en experiencias reales (de otros investigadores).

Para la obtención de la información primaria y su posterior análisis se realizaron entrevistas abiertas cualitativas a informantes clave, y se procedió a la observación directa en los medios de trabajo. La selección de las unidades de muestra ${ }^{1}$ se ha realizado tratando de equilibrar la presencia de directivos, mandos intermedios, administrativos y operarios, dada la importancia de obtener múltiples puntos de vista desde diferentes ángulos de la pirámide organizacional por las exigencias del tema (comunicación vertical). El polémico contenido de las observaciones nos ha llevado a no desvelar la identidad de las empresas analizadas, si bien las investigaciones de las que fueron objeto de estudio quedan especificadas en la bibliografía.

1 Se trata de una muestra no probabilística y razonada por decisión subjetiva. 


\section{Antecedentes teóricos}

Entre los frentes fundamentales para entender la sociología de la empresa se encuentran la participación y el poder, tal y como confirman los casos analizados. Desde que la Escuela de las Relaciones Humanas, de la mano de Kurt Lewin, destacó en los años sesenta del pasado siglo los beneficios que el estilo de liderazgo democrático aportaba a las organizaciones, los analistas se han empeñado en medir el grado de participación fomentado y permitido entre sus miembros. El grado de participación de los distintos actores está directamente vinculado con la distribución del poder, que se manifiesta en los procesos de toma de decisiones, en la representación y, desde luego, en la comunicación, ya que, como destacó Charles Perrow en 1994, la distribución, la canalización, la distorsión y el bloqueo de la información se utilizan para delimitar el acceso a posiciones de privilegio en las organizaciones. Entre las dificultades que encuentran las organizaciones para gestionar su comunicación, la vertical resulta especialmente compleja por cuestiones como las diferencias de poder y de clase social (Gil Estallo: 2001b). Estos problemas centrarán la atención de nuestro estudio.

Las formas de comunicación interna dentro de la organización estarán forjadas, principalmente, por sus pautas culturales. La existencia de estos hábitos y costumbres (cultura organizacional) en el interior de las empresas las dota no sólo de estabilidad, sino también de una identidad propia, que Selznick (1957) denominaba «carácter». Dicho carácter distintivo, que es lo que convierte a la organización en institución, estará determinado por la historia de la organización y, especialmente, por sus decisiones críticas, en las que realmente se hace notar la personalidad y el estilo de sus directivos. «El carácter de una empresa es resultado de un proceso histórico en el que intervienen las decisiones críticas que tuvo que adoptar anteriormente, y las soluciones que se adoptaron. La naturaleza de las decisiones anteriormente tomadas dependen de la interacción mantenida por la organización y su entorno en el pasado.» (Lucas Marín, 2002: 183).

Este carácter propio, que se imprime a través de la tradición, determina la verticalidad de la estructura de la organización y también el estilo de su comunicación. En la formación de estos aspectos interviene de forma muy notable la personalidad de los líderes de la compañía, muy marcada, a su vez, por las primeras experiencias vividas por la organización. Los acontecimientos negativos marcarán los temores y precauciones de la organización, y los positivos reforzarán determinadas maneras de hacer las cosas. Obsérvese el importante papel que se otorga a los primeros pasos en cualquier documento divulgativo de la historia de la organización. El estilo de comunicación y los sistemas adaptados dependerán de la cultura de empresa previamente gestada ( $y$ no al contrario), de ese «carácter» forjado con el tiempo que resulta tan determinante. 
También en la línea del determinismo cultural de los sistemas de comunicación, Stefanova y Lucas Marín (2007: 301) afirman: «La cultura contribuye al funcionamiento interno de la organización, al dar lugar a un factor importante de cohesión y de intercambio de información. Ésta interviene favoreciendo las conductas útiles para el logro de objetivos colectivos. Por otra parte, la cultura juega un importante papel estabilizador para la organización, pues una vez establecida evita la necesidad de repetir continuamente las normas, los procedimientos y los modos de hacer propios de cada organización».

Para Wei Choo (1999), la importancia de la gestión de la comunicación vertical tampoco ha pasado desapercibida — en su modelo de organización inteligente - ; este autor destacaba como una de las claves para el correcto funcionamiento informativo de la empresa la transformación del conocimiento tácito (privado) en conocimiento explícito, que enriquezca el patrimonio organizacional. En esta misma línea, Peter Drucker (2000:6) destacó que «los conocimientos estarán en la parte baja de la pirámide jerárquica, en la mente de los especialistas que realizan diversos trabajos y se dirigen a sí mismos». Este analista entiende que muchas de las deficiencias o puntos débiles de la comunicación vertical podrían evitarse recurriendo a mecanismos de feedback previamente probados. La comunicación ascendente se convierte, de este modo, en una herramienta que proporciona una importante retroalimentación que fomenta la eficacia de las comunicaciones descendentes y, por lo tanto, contribuye a paliar los problemas de la organización. De esta forma, los trabajadores pueden plantear sus sugerencias para la solución de conflictos o propuestas de mejora, así como realizar sus quejas.

Según el equipo del Laboratorio de Psicología del Trabajo de la Universidad Complutense de Madrid, formado por Jaén, Luceño, Martín y Rubio (2006), con la información descendente las organizaciones suelen descuidar aspectos como los objetivos y resultados de la organización, siendo demasiado específicos sobre las tareas concretas que desarrollar. En tales casos, se recomienda la aplicación de reuniones de trabajo que faciliten el feedback y el briefing (si se trata de un proyecto concreto), así como la elaboración de guías de empresa o boletines periódicos. Por otra parte, en la ascendente escasean los canales de información previamente establecidos. Ante esta falta de gestión, es frecuente que los empleados no se atrevan a improvisar sus propios canales por temor a la reacción de sus superiores y por la presumible falta de utilidad del comunicado. En algunos casos, los directivos se sienten cuestionados o desafiados, y refuerzan los mecanismos para que la comunicación continúe siendo unidireccional. Las herramientas que permiten la difusión de la comunicación ascendente son los cír- 
culos de calidad, los sistemas clásicos de sugerencias, los cuestionarios y la aplicación del método Phillips $66^{2}$.

En esta línea, Brunet y Alarcón (2006: 351) perciben la adecuada gestión de la información ascendente como una de las piedras angulares de su modelo de aprendizaje en las organizaciones: «Existen técnicas para impulsar el aprendizaje organizativo, como el Metaplan. En ella se trabaja en sesiones de grupo, procurando la implicación de todos los asistentes, la precisión en la presentación de argumentos e ideas, la optimización del uso del tiempo y la consecución de los objetivos de aprendizaje organizacional previstos; interviene un moderador cuya principal tarea consiste en visualizar las discusiones, promover la interacción entre los participantes y plantear una secuencia precisa de preguntas que haga aflorar la información en el seno del grupo. [... Esta forma de actuar está relacionada con una constante indagación en el seno de la organización que le permita un aprendizaje fructífero en base a preguntarse continuamente el porqué de las cosas».

Para Alamillo (2008), las mejores empresas son aquellas en las que existe comunicación abierta entre empleados y niveles superiores, ya que los empleados son generadores de utilidad y debemos valorarlos más allá de su sueldo. En las conclusiones de los estudios de organizaciones industriales leemos frecuentemente que los niveles altos no se preocupan por la sobrecarga de trabajo, que no escuchan a los empleados y que se vuelven reactivos ante los empleados que plantean un problema o alguna cuestión mejorable. Estas ideas vienen a confirmar las aportaciones de Kotler y McKenna (1998), que destacaban la escasa habilidad desarrollada por los directivos en relación con la escucha activa en las organizaciones. Nuestros progresos parecen haber escogido otras actitudes.

\section{Problemas y disfunciones de la comunicación vertical en las organizaciones}

Los problemas propios de la comunicación en las organizaciones tradicionalmente estudiados se ven agravados en contextos de comunicación vertical por la asimetría existente entre los diferentes grupos con presencia en las organizaciones, que, a su vez, son producto de la «casi siempre» inevitable jerarquía. El desarrollo del clásico modelo de organización piramidal, de generalizada difusión desde principios del siglo $\mathrm{xx}$, ha pasado factura a los sistemas de comunicación. A continuación, tratamos de exponer

2 Phillips 66: técnica organizativa utilizada para generar calidad en la información ascendente. Los participantes, reunidos en grupos de seis, analizan un problema concreto de la organización y generan una serie de ideas previas, que luego debaten y transforman en una propuesta para la dirección (http://infocop.es). 
los problemas específicamente vinculados a la comunicación ascendente y descendente en las organizaciones con mayor presencia en la literatura, destacando, cuando proce$\mathrm{da}$, su presencia en los casos de organizaciones analizadas.

1. Control del tiempo: las presiones de tiempo, tan características en nuestra actual sociedad, suponen una barrera en las comunicaciones. Es frecuente que los directivos aleguen falta de tiempo para comunicarse con sus subordinados. Un problema clásico identificado con estas omisiones de información es el cortocircuito. Se trata de un fallo en el sistema de comunicación provocado por el salto de eslabones de la cadena como consecuencia de las presiones de tiempo. Es frecuente que los empleados recurran a un directivo que les debe un favor en situaciones de fuerte presión de tiempo para resolver una gestión. El problema surge por la tendencia que algunos directivos tienen a esconder una información no favorable a sus intereses - en este caso, supongamos que autoriza una dieta sin el visto bueno del cargo intermedio-, con lo cual en ese eslabón se desconoce que se ha hecho una excepción y se ha producido un gasto extra. La generación de estos puntos ciegos tiende a generar conflictos (Gibson, 1999).

Las presiones de tiempo propias de algunos roles nos llevan, en ocasiones, a trasmitir las órdenes a gran velocidad y sin explicaciones, generando la lógica confusión en el siguiente eslabón de la cadena. Uno de los directivos de la compañía de transportes analizada se defendía así al plantearle este asunto:

«Aquí, para dirigir algunas operaciones, no hay que ser paternalista. Vamos a ver [...] yo no puedo perder mi tiempo en explicar cómo se hace un trabajo, sé qué ocurre, y por qué ocurre, y no es el momento de explicarlo, porque estoy interrumpiendo una emisora de comunicaciones. Aquí la clave está en producir [...], no hay tiempo para parafrasear» (directivo de multinacional del transporte).

Otro de los puntos conflictivos es la capacidad que otorgan algunos puestos estratégicos, que no siempre son los de mayor estatus, para recibir, congelar y distribuir la información, lo que permite al actor, en ocasiones, realizar maniobras que aseguren su posición de privilegio. El momento en que se transmite la información es clave, de modo que, en ocasiones, acelerar o desacelerar un comunicado marca la diferencia entre ganadores y perdedores. Los privilegios en el control del tiempo actúan también como factores generadores de tensión en las comunicaciones verticales. La información solicitada asciende rápidamente, mientras que desciende rápida o lentamente en función de las circunstancias e intereses que se dan en los cuadros dominantes (Vallejo Peña, 2007).

«Me buscan de la central y, ; tremendo!, tengo que dar una respuesta al momento; ahora bien, si hay precipitación la culpa es mía. [... A Ahora que, cuando yo les pido cosas a ellos, puedo esperar sentado» (mando intermedio en multinacional del transporte). 
Estas circunstancias nos invitan a recordar a Pfeffer (1999), quien destacaba que los tiempos de espera a que éramos sometidos eran auténticas demarcaciones de poder de los actores de nuestro entorno. Si realmente quieres saber cuál es tu posición en la organización, dime cuánto esperas y cuánto te hacen esperar.

2. Problemas semánticos: los errores cometidos por los actores en la utilización de las palabras, así como las dificultades que encontramos para compartir su interpretación. Una misma frase implica distintos significados para diferentes receptores. La utilización de un comunicado de la dirección de la compañía plagado de tecnicismos provocará que sea interpretado de múltiples formas según la cualificación de los receptores. También debemos considerar disfuncional la utilización de frases imprecisas, no demasiado claras o que dejen varias opciones abiertas al receptor. En algunas ocasiones, la imprecisión se da por carencias del comunicador; en otras, de forma intencionada, para manejar una situación en que no interesa dar a los receptores datos precisos: por ejemplo, «se tomarán medidas próximamente». En otros casos, el equipo directivo no adapta el mensaje a la capacidad técnica de un estrato que maneja otras jergas y que puede desconocer el vocabulario, o al que, sencillamente, le faltan referencias contextuales para entender el mensaje.

3. Juicios de valor: el receptor formula juicios de valor sobre su emisor que suponen asignar un prejuicio a su mensaje antes de recibirlo íntegramente. Éstos se basarán en las experiencias anteriores con el comunicador, el rol que desempeña en la organización $y$ en situaciones que se relacionan con el mensaje. Si el directivo no escuchó nuestras peticiones ni apreció nuestra participación, podrá generar en sus subordinados una sensación de desidia (Gibson, 1999: 657). Por ejemplo, un profesor universitario que considera que el decano de su Facultad no se preocupa demasiado por la calidad de la enseñanza impartida, puede entender que la reunión convocada por esta persona para evaluar sus méritos es pura rutina, por lo que acudirá a ella con absoluta pasividad ${ }^{3}$. En el seno de las organizaciones tendemos a gestar prejuicios sobre el comportamiento de otros grupos con diferente estatus, lo que genera, en ocasiones, un ambiente de mutua incomprensión.

Observando un supuesto en la comunicación descendente, se puede notificar a todos los departamentos operativos que deben reducir sus costes para que la organización aumente beneficios. Puede suceder que la comunicación no obtenga los efectos deseados por entrar en conflicto con la forma como sus perceptores afrontan la «realidad».

Problemas similares encontramos en el caso de los comunicados ascendentes. Imaginemos que un grupo de trabajadores redacta una reclamación dirigida a su gerente, en la que solicita que se hagan algunos descansos más allá de los ya establecidos dentro

3 Ejemplo extraído de Gibson, C. (1999), Organizaciones. McGraw Hill. Pág. 657. 
del tiempo de trabajo. Para justificar esta petición, alegan los problemas oculares que presentan los trabajadores como consecuencia de las prolongadas sesiones ante el ordenador. Esta circunstancia viene reforzada por el último informe de la asistencia médica. El gerente ignoró el comunicado y se limitó a comentar con el resto de los directivos de la empresa que el desgaste visual de los empleados venía provocado por el plus de horas de ordenador dedicadas a asuntos propios.

4. Problemas de jerga, idioma, cultura y religión: siempre generan barreras de comunicación, refuerzan los estereotipos y, por lo tanto, implican presunciones y malentendidos. Las jergas organizacionales otorgan a sus diferentes grupos sensación de pertenencia, cohesión y autoestima, contribuyendo también a una comunicación eficaz; si bien, al mismo tiempo, provoca algunas disfunciones que sufren especialmente las personas ajenas al grupo. Esta situación se hace especialmente patente cuando el grupo no la usa para comunicarse, sino para reforzar su propio carácter. Asimismo, en las multinacionales en que se hablan varios idiomas, las rencillas y malentendidos son frecuentes. Recordemos que quien se esfuerza en hablar el idioma del otro muestra respeto y adaptación, mientras que se puede utilizar el idioma propio para mostrar al grupo ajeno hostilidad ${ }^{4}$. Si a las diferencias idiomáticas sumamos otras de carácter cultural o religioso, el cóctel se complica aún más. Los motivos religiosos pueden afectar a cuestiones básicas de convivencia en la organización, como el diseño de los menús y de los horarios. Imaginemos el caso de una compañía que incluye cerveza en el menú ante una mayoría en la plantilla que censura el consumo de alcohol por su religión, o bien la polémica carne de cerdo. En el caso de los horarios, debemos pensar en la ortodoxa utilización de los sábados o los domingos en algunas religiones. Existen notables dificultades en la gestión de empresas a la hora de entender, particularmente, cuestiones religiosas.

5. Orientación a la tarea: en ocasiones, nos sentimos presionados para finalizar nuestras tareas con rapidez y para alcanzar altos niveles de concentración. En consecuencia, nos bloqueamos y nos aislamos ante comunicados importantes. A veces, el trabajador centra su atención inútilmente en una tarea que no reporta los beneficios deseados para la empresa, y termina descuadrando la organización de su tiempo. Los

4 «Pero yo, con mucha dignidad [...] desde el principio entraba como hacía siempre y le planteaba cosas $[. .$.$] y se me quedaba mirando como que yo venía a traerle problemas. Le llevaba un$ problema para que le diera posibles soluciones. Yo llegaba con un problema y además salía con otro, porque además salía disgustado con él. Pensaba que era el idioma, y yo intentaba decírselo en inglés, pero tampoco. Desde esa fecha yo no veo a mi jefe a lo largo del día, pero yo no me quedo ahí, y mis ideas las llevo a la práctica ¿sabes como? A través de otras personas; pero así me voy a casa tranquilo. Pero yo a ellos no les llevo ni una idea, ¡ni una! [... ] Hay un jefe que no sabe entender a los trabajadores, que en este caso es danés, pero hay españoles también [...]» (técnico de multinacional del transporte). 
directivos raramente saben anteponer a estas tareas rutinarias cuestiones tan relevantes como los objetivos a medio plazo de la compañía o las características del próximo cliente al que serviremos (Jaén y Luceño, 2006). Pongamos el caso de un trabajador que debe presentar un informe de resultados trimestrales a la mañana siguiente a un exigente directivo de su compañía. Voluntariamente, se aísla toda su jornada de cualquier medio de contacto con su empresa y termina dignamente su trabajo. Al día siguiente, conoce la desesperante noticia de que su jefe ha debido desplazarse urgentemente fuera del país para intervenir en un conflicto negociador, y antes de marchar se disculpó ante los técnicos pidiendo que en el siguiente informe trimestral le entregaran un resumen del anterior. En esta línea, algunos profesores, como es mi caso, tenemos la costumbre de pasar por la conserjería del centro para revisar los mensajes entre clase y clase, para compensar el inevitable aislamiento del entorno que supone impartirlas.

6. Diferencias de nivel entre los cargos (estatus): se trata de la piedra angular de la problemática de la comunicación vertical en organizaciones. Sobre este problema se cimientan las barreras que se analizarán a continuación. Los diferentes estatus y la desigualdad de clase marcan barreras de comunicación por los distintos códigos utilizados, presunciones erróneas, distintos intereses y sistemas de valores. La desigualdad puede desatar competencia insana y dañinas envidias en el seno de la organización. Como consecuencia de la asimetría existente en las relaciones y comunicaciones entre los distintos niveles de la organización, debemos destacar la opacidad de la información directiva. La dirección no soporta la misma presión para informar de sus resultados y proyectos al conjunto de la organización que el resto de sus componentes. Por otra parte, la posibilidad de ocultar información depende, claramente, de las diferencias de estatus entre los grupos.

7. Desprecio de la escucha activa escuchar activamente es una virtud reconocida en las personas y en las organizaciones. Frecuentemente nos encerramos en nuestro punto de vista o en el de un carismático líder que, desde luego, no siempre acierta. Poner en práctica la escucha activa (Kotler, 2000) implica considerar las opiniones de personas de cualquier estatus en la organización, para realizar, posteriormente, una valoración crítica de dicha información. Sin embargo, a las empresas que tratan de ponerla en práctica les resulta difícil mentalizar a los directivos para que escuchen a sus subordinados. El problema se acrecienta por el hecho de que, en ocasiones, los empleados trabajan en contacto directo con los recursos de la organización y pueden proporcionar un punto de vista in situ inalcanzable para los puestos superiores.

8. Lectura anticipada de las cuestiones de fondo: ante determinadas maniobras de la organización, las cuestiones de fondo que las condicionan son sólo perceptibles para quienes manejan información privilegiada. Se trata de personas cercanas al poder que pueden acceder, por vía formal o informal, a la doble lectura de los asuntos orga- 
nizacionales. En el mundo de la alta dirección de empresas, se maquilla con frecuencia una brusca salida de la organización argumentando problemas en la vida privada del directivo, con objeto de dejar las verdaderas razones de su marcha a la luz de una minoría. Determinadas posiciones permiten a algunos individuos manejar información privilegiada, mientras que los demás especulan con complicadas averiguaciones.

9. Atención selectiva: las personas tienden a bloquearse ante cualquier nueva información cuando no comparten las ideas subyacentes. Por ejemplo, al leer un comunicado de otro departamento de la misma compañía, el receptor tiende a retener los contenidos que confirman su propio discurso. Lo que entre en conflicto con sus ideas preconcebidas lo ignorará o distorsionará, para confirmar sus opiniones anteriores. Nuestros discursos, a su vez, están marcados por cuestiones como la clase social y el estatus en la organización, lo que genera en el seno de la organización las citadas barreras. En esta línea, Krombarg (1999: 112) reflexiona así como sigue: «Observando un ejemplo en la comunicación descendente, se puede notificar a todos los departamentos operativos que deben reducir sus costes para que la organización aumente beneficios. Puede suceder que la comunicación no obtenga los efectos deseados por estar en conflicto con la forma en que sus perceptores perciben la 'realidad'. Por lo tanto, cabe pensar que los empleados de dichos departamentos operativos ignoren o, simplemente, se 'diviertan' con esta información a la vista de los enormes salarios, dietas de viajes y cuentas de gastos con que cuentan algunos de sus directivos. El hecho de que estas ideas preconcebidas estén o no justificadas carece de importancia; lo que importa es que dan lugar a fallos en las comunicaciones. Si sólo oímos lo que queremos oír, nuestra realidad jamás se verá afectada ${ }^{5} . »$

Por otra parte, hemos de señalar que uno de los defectos más denunciados sobre los directivos de las compañías analizadas es la atención prestada repentinamente al empleado cuando comete un error, que le puede llevar a convertirse en protagonista negativo por un solo día, independientemente del trabajo cotidiano realizado y la regularidad mostrada. En palabras de uno de los informantes de la multinacional del transporte analizada:

«En nuestra empresa, los mandos intermedios tienen que estar muy atentos, tienen que estar continuamente en comunicación con la empresa. A veces han caído broncas tremendas de la central porque alguien no estaba localizable» (mando intermedio en multinacional del transporte).

10. Credibilidad de la fuente: el grado de credibilidad que el receptor asigna al comunicador afecta, a su vez, directamente a la forma como el receptor considera y reacciona ante las palabras, ideas y actos del comunicador. El estatus-prestigio asignado al agente resulta esencial. Por consiguiente, el valor que los subordinados asignan

5 Este ejemplo ha sido extraído del manual de Krombarg, C. (1999), Organizaciones. McGraw Hill. 
a sus superiores afecta a su opinión sobre las comunicaciones que reciben de ellos. Igualmente, es destacable la consideración que el directivo asigna al empleado que le transmite un comunicado y, frecuentemente, se desestiman opiniones de personas con un estatus inferior en la organización, ya sea por su rango o experiencia. Uno de los informantes de rango directivo analizados en la empresa de transportes nos contestaba en estos términos al preguntarle sobre el tratamiento de las sugerencias y quejas de sus empleados:

«Lo que pasa es que a los directivos, por nuestra actividad, es muy fácil que se nos ocurran ideas. En los operarios es diferente [...]» (directivo de multinacional del transporte).

Como afirmó Umberto Eco $(1977$ 43) en uno de sus trabajos, «En ocasiones las organizaciones pecan de soberbia en la gestión del conocimiento». Aumentar nuestra capacidad para abrirnos a una amplia variedad de opiniones y construir nuestra propia crítica sería determinante.

11. Canales e intermediarios: los canales utilizados en la organización para transmitir la comunicación no son siempre nítidos y precisos. Esta circunstancia es muy palpable en el caso de los medios materiales (faxes que llegan borrosos, correos electrónicos devueltos, problemas en la cobertura telefónica, etc.). De modo similar, la numerosa red de intermediarios a que recurre la organización para transmitir la información dificulta muchas veces la claridad de los mensajes: un largo camino en el que se difuminan las responsabilidades, pero también la nitidez de la información. En la comunicación descendente, los intermediarios se utilizan con frecuencia para reducir la tensión de los directivos ante mensajes conflictivos y poco populares para los trabajadores. Para estos últimos, las decisiones «sin dar la cara» se convierten en un motivo más de insatisfacción. En la compañía de transportes analizada se recogió el siguiente testimonio:

«En los canales se desvirtúa, ya sabes lo que pasa, de forma que muchas veces, cuando llega al último, llega desvirtuada la información y pierde muchísimo. En general, digamos que es buena, pero con bastantes lagunas en la comunicación descendente; a veces los mensajes no se entienden [...]» (directivo de multinacional del transporte).

En esta línea, debemos destacar también las dificultades que genera la comunicación vertical bifurcada, es decir, la que se da en situaciones en que los mandos ordenantes no comparten opiniones. El caso que se muestra a continuación, recogido de una industria metalúrgica belga de tamaño medio, es un buen exponente de lo espinoso de estas situaciones:

«¿Por qué no preparó el envío para despacharlo mañana, Sr. Vanderlickt?», pregunta el hijo mayor al jefe de producción, al bajar a la sala de maquinaria y ver que la mercancía no se ha empaquetado para enviarla al día siguiente. 
«Creí que su padre se lo había dicho, Sr. Vassel. Bajó a mediodía para controlar a los obreros y ver la maquinaria, pero cuando yo terminaba de despachar la mercancía que Ud. me ordenó hoy, su padre me dijo que cancelara todo envío para mañana, hasta que no se acordaran nuevas medidas con la Cámara de Comercio», declara el jefe de producción al joven heredero.

«Papá me va a escuchar [...]. No entiende, no entiende. Estamos atrasados en los envíos [... . No sabe, si se ha quedado en el tiempo [... ]», murmuraba para sí el futuro dueño de la fábrica mientras regresaba a su oficina enconado, apretando los puños con fuerza. Mientras, dos obreros hablan por lo bajo: «Cuando mande éste yo me voy [...]. Tú hazle caso a los dos y no tendrás problema alguno, y si lo tienes ve y dile al hijo pequeño, que ése sí que sigue todo lo que dice el padre, y asunto arreglado», le responde al primero, quien sigue: «Claro, tú lo haces fácil, pero nuestro próximo patrón no es el hijo pequeño, sino el mayor [... . ¿Quién los entiende a éstos? En un sólo día veinte órdenes diferentes [...], como para seguir directivas así. Luego hay problemas en la producción y cargamos nosotros con la culpa, cuando los problemas en realidad los generan éstos, que no se aclaran ni ellos» (diálogo en industria familiar de tamaño medio).

En la situación aquí analizada observamos que, en la comunicación horizontal, se generan mensajes contrapuestos, de lo que se sigue un fallo en la fase de envío de mensajes en la comunicación descendente; la comunicación vertical llega filtrada (pues se da a los obreros a través de jefes de planta, de producción o secretarios) y se reciben diferentes versiones del mensaje. Estamos ante una comunicación vertical bifurcada, ya que las dos fuentes de poder generan al mismo tiempo mensajes diferentes. En situaciones como la de esta fábrica belga, uno de los jefes acabará perdiendo el estatusrol del ordenante. Tal y como señaló Bordieu (1980ः38), «al no ser legitimado quien manda, o quien cree tener el mando, pierde el poder, y por ende no es reconocido como autoridad y no se siguen sus órdenes». En este caso no sólo se advierte conflicto y ambivalencia en el poder; también se puede observar la intrínseca interdependencia entre la comunicación horizontal y la vertical.

13. Filtraciónः en el mundo organizacional, la manipulación de la información por parte del emisor para que el receptor la considere positiva es una práctica muy común. Por ejemplo, los subordinados ocultan cualquier dato desfavorable al informar a sus superiores. Ésta es una disfunción muy propia de la información ascendente, que defiende los intereses privados de los actores - a veces más que los de la propia organización - al transmitir comunicados a sus superiores. Recuérdese que la dirección de la empresa valora los méritos, aumenta los salarios y concede ascensos a partir de la información recibida a través de los canales ascendentes, y que no siempre se ajusta con precisión a la realidad dados los intereses de los actores (Gibson, 1999). 
14. Aspectos proxémicos: entendemos por proxemia el componente de la comunicación no verbal que trata la utilización del espacio en las comunicaciones interpersonales. «La proxemia distingue varias zonas. Desde el contacto físico hasta los 45 centímetros, hablamos de zona íntima; desde los 46 centímetros hasta los 125, de zona personal; a partir de 126 centímetros y hasta los 4 metros, de zona social; y por último, la zona pública, con distancias de más de 4 metros» (Hunsaker, 1980: 41). La proxemia se genera en la propia sociedad con carácter funcional y está dirigida, claramente, a mantener el orden social. El problema aparece en las organizaciones cuando dos o más interlocutores tienen un comportamiento proxémico diferente. El tratamiento de las distancias físicas puede variar con la clase social o la cultura, lo que provoca que podamos violentar inconscientemente a nuestro receptor. Otro problema de comunicación se da cuando el emisor utiliza deliberadamente la proxemia para hacer notar la distancia de estatus, o anularla a su conveniencia. Por ejemplo, pensemos en el directivo que en una reunión con sus subordinados exagera la distancia física hasta alcanzar el nivel público (más de cuatro metros), con la intención de que no le pidan favores comprometedores. Ahora bien, imaginemos la reacción de estos trabajadores cuando, tras tener lugar la cena de Navidad de la empresa, el mismo directivo busca la proximidad física compartiendo unas copas, tratando de compartir información como si fuera uno más en la reunión. En este contexto, pensaremos que nuestro superior pretende obtener alguna filtración que le favorezca, lo generará un clima de desconfianza.

15. Selección de lugares y eventos adaptados al mensaje: entre las debilidades observadas aparece la inadecuada utilización de espacios y eventos para emitir determinados comunicados. A veces «lo que se dice» no es coherente con «cómo y dónde se dice». Estas situaciones se han presentado en el caso del centro educativo analizado. Se anuncia una reunión docente de despedida y festejo de fin de curso y, sorprendentemente, se exponen en ella evaluaciones, balances, porcentajes de aprobados y suspensos. La intención funcional difiere claramente de la motivacional. Como consecuencia de la ambigüedad del evento, encontraremos falta de credibilidad del mensaje en el ambiente de trabajo, enorme confusión generada en el grupo y una mala predisposición para encuentros futuros, temiendo próximos dobles-mensajes, con dificultades para distinguir dónde se encontrará la botella de champán o el tirón de orejas. Si no se muestran de forma transparente los fines de nuestro comunicado y la respuesta de los demás, pueden constituirse en obstáculo para las buenas relaciones y el diálogo.

«Imagínate la sorpresa al estar allí, pensando en echar un rato de charla tranquilos y de repente empezar a leer datos [...]. Podrían haber dejado el asunto del balance anual en unas palabras amables y ya veremos otro día cómo solventar los problemas» (docente en centro educativo de Formación Profesional). 


\section{Conclusiones}

Tras la realización de nuestro análisis, nos ha llamado considerablemente la atención la aparición, en los testimonios de los informantes, de un discurso crítico en la clase directiva hacia los sistemas de comunicación de sus propias organizaciones (entre los operarios ya era previsible). La inmensa mayoría destaca la importancia de ajustar el sistema para evitar lagunas en la transmisión de la información. Nuestra expectativa era encontrar el discurso crítico concentrado en los estratos inferiores de la organización, por la presión soportada desde arriba. La extensión de las denuncias hacia la parte alta del organigrama ha sido una primera sorpresa, distante de nuestras hipótesis iniciales. Entendemos que los directivos son cada vez más conscientes de la importancia de dinamizar los sistemas de comunicación para hacer a sus empresas más competitivas (en parte, gracias al importante desarrollo reciente del campo), aunque las dificultades aparecen cuando se plantean las propuestas para mejorarlos.

Los principales científicos organizacionales coinciden en identificar un enorme nicho de problemas en la comunicación vertical. Las organizaciones implican sistemas de estratificación social y de distribución asimétrica del poder. Las desigualdades nunca facilitaron la comunicación entre los grupos sociales que comparten el mismo ámbito organizacional. Así ha sucedido en cualquier ámbito de la vida, y el mundo empresarial y organizacional no es una excepción. Los distintos grupos que dan forma a la organización manejan distintos códigos, valores y metas, unas veces divergentes, otras contrapuestos. Como siempre, los grupos más favorecidos acceden a informaciones privilegiadas, tempranas (llegan antes), y tienen mayor control sobre los sistemas de comunicación. De esta forma, las élites pueden manejar sus cartas con ventaja, priorizando entre sus objetivos el mantenimiento del poder, aunque esto no se traduzca siempre en la eficiencia del proyecto colectivo.

En definitiva, podemos concluir que las organizaciones actuales pierden potencial informativo por los problemas anteriormente citados, $y$, por lo tanto, productividad. El poder genera conductas soberbias que hacen a los directivos perderse numerosos detalles sobre el funcionamiento de su organización. Así mismo, los empleados pierden aliento y motivación cuando observan que sus peticiones y sugerencias son como un mensaje en una botella lanzada al mar. Para evitar estas disfunciones, las empresas deben emprender cambios a través de la gestión activa de su propia cultura (Hofstede, 1999).

En esta línea, el management moderno se ha visto abordado por una nueva tendencia, que cuenta con su corroboración científica en la teoría organizacional: la escucha activa (Kotler, 2000). La empresa moderna debe cultivar su oído e incorporar la escucha a sus hábitos y costumbres. A través de ella potenciaremos la obtención de infor- 
mación extra en forma de feedback. El enfoque institucional destacaba estos aspectos desde la difundida teoría de la racionalidad limitada (March y Simon, 1958), en la que se nos recordaban las imperfecciones de nuestras decisiones organizacionales, asumidas siempre sin la información deseada sobre el mercado y el entorno. No obstante, el arte del management estribaría en ser hábiles tomadores de decisiones, aun reconociendo la existencia de zonas de incertidumbre no controladas por el directivo.

Tratando de evitar planteamientos pesimistas, la moderna dirección de empresas puede recurrir a la explotación de nuevas fuentes de información despreciadas e ignoradas hasta hace muy poco. Desde el marketing hasta la gestión de recursos humanos, una nueva tendencia inunda las lecciones impartidas en escuelas de negocios de todo el mundo: escuchen a su entorno, a los clientes externos y, también, a los internos. Cualquier transacción en una simple venta de un bien o servicio puede aprovecharse para obtener información valiosa para la organización. A veces, el dato más sustancioso se encuentra en detalles imperceptibles a primera vista. Todos somos conscientes de que somos utilizados como consumidores o clientes para la obtención de datos personales que las organizaciones recogen en masivos trabajo de campo. Rellenamos cotidianamente formularios o pequeñas encuestas para contratar servicios con los que las empresas infieren nuestra clase social, gustos, preferencias y nivel de renta, entre otros. Algunas empresas adiestran a sus empleados para realizar periódicamente observaciones cualitativas sobre las reacciones de los consumidores tras la prestación de servicios (se trata de una técnica muy explotada en el sector turístico). Hasta la protesta de un cliente al girarse tras firmar la recepción de un pedido contiene información interesante para la organización. Los departamentos de reclamaciones, además de proporcionarnos datos sobre nuestras lagunas e imperfecciones, ofrecen una gran oportunidad para realizar escucha activa. Los sistemas para recoger y analizar estas informaciones no son demasiado costosos hoy día, y la empresa puede sacarles un gran rendimiento, si las utiliza constructivamente (Kotler, 2000). Otro tanto sucede con nuestros clientes internos - los miembros de la organización-, de quienes obtenemos un feedback continuo. Las organizaciones han ido incorporando a su cultura la percepción de los departamentos a que se presta servicios como clientes, de cuya satisfacción dependerá el funcionamiento armónico del sistema y, por consiguiente, la producción.

En este sentido, retomando la perspectiva interpretativa de Max Weber, la auténtica conciencia crítica de una organización se genera a través de la multiplicidad de puntos de vista que ofrecen los actores. La diversidad facilita la visión desde diferentes ángulos de la organización y la huida de los prejuicios que nos llevan continuamente a situaciones de «callejón sin salida». Recuérdese que las nuevas tendencias de gestión participativa dependen, más que de la aplicación de técnicas concretas, de una filosofía y de su proyección hacia una cultura de empresa acorde con ésta por parte de los 
líderes, si bien su aplicación precisa de la creación de foros y espacios de comunicación donde los actores de la participación tomen la palabra. Estas acciones generarán efectos positivos sobre la organización en los casos en que se haya logrado previamente fomentar actitudes y predisposiciones propias de la escucha activa.

Otro aspecto importante que considerar en la comunicación vertical es la transmisión de mensajes a través de la estructura informal. Las relaciones informales generadas en el entorno de la organización desembocan en atajos hacia el poder. La teoría organizacional siempre enfatizó la importancia de estas relaciones, que a veces desbordan las facultades de la organización formal. Una buena dinamización de las relaciones informales agiliza los sistemas de comunicación dentro de la empresa. Por otra parte, las relaciones sociales existentes en el exterior de la organización condicionan los comportamientos internos, tal y como destaca Aquiles Chihu (2006: 29): «el poder se construye y funciona a través de otros poderes, de los efectos de éstos, independientes del proceso económico. Las relaciones de poder se hallan estrechamente ligadas a las familiares, sociales, productivas; íntimamente entrelazadas y desempeñando un papel de condicionante y condicionado». Préstese atención a la influencia de las relaciones familiares en el entorno institucional, así como al hecho de que algunos directivos sean fichados por las empresas exclusivamente por su capacidad para las relaciones sociales.

Los comunicados deficientes que provocan desajustes en el interior de la organización — véase el caso planteado de la fábrica metalúrgica - vienen causados por conflicto de poderes y por una exagerada comunicación verticalista, y, a su vez, pueden desembocar en una notoria anomia social. La anomia viene provocada por la falta de normas en un determinado grupo social. Se da, según Peter Heintz (1965), cuando las regulaciones o normas para llegar a las metas que se fija una sociedad no son claras, o no permiten llegar a ellas a algunos sujetos por su mala ubicación en el sistema (marginalidad). Otro factor generador de anomia es la promoción en una sociedad de excesiva competencia entre sus miembros sin llegar a definir con claridad los límites y normas establecidos para alcanzar las metas.

Frecuentemente, en las organizaciones modernas las órdenes que llegan a los operarios no son claras; otras veces son contradictorias, por la bifurcación de poderes anteriormente comentada. Esto genera en los actores un estado de apatía y desinterés generalizado, de absoluta oscuridad respecto a los objetivos y metas que alcanzar. La ambigüedad, la falta de feedback y la incomprensión equivalen a situaciones de desorientación entre el personal y, por ende, a confusión en las metas y objetivos, lo que da lugar a situaciones de anomia.

Finalmente, hacemos un llamamiento al lector para que trate de vincular las anteriores reflexiones a sus propias experiencias personales en organizaciones: ¿qué casos 
hemos vivido en que se hayan dado estas circunstancias? ¿Son también defectos de nuestras organizaciones? El debate será, sin lugar a dudas, inagotable.

\section{Bibliografía}

Alarcón, A. y Brunet, I (2006). «Aprendizaje organizacional», en Brunet, I. y Alarcón A. (2006). Sociología de la empresa y de las organizaciones. Zaragoza: Egido, págs. 345-359.

Bourdieu, P. (1980). Le sens pratique. Paris: Minuit.

Chinu Amparán, A. (2006). El análisis de los marcos en la sociología de los movimientos sociales. México: Universidad Autónoma Metropolitana.

Drucker, P. (2006). Los desafíos en un mundo sin fronteras. Barcelona: Edhasa.

Eco, U. (1999). Cómo realizar una tesis doctoral. Barcelona: Gedisa. (1977; primera edición.)

Gibson, C. (1999). Organizaciones. Madrid: McGraw Hill.

Gil Estallo, M. A. (2001a). Empresa virtual, de la idea a la acción. Madrid: ESIC.

Gil Estallo, M. A. (2001b). Organización y administración de empresas. Barcelona: Universitat Oberta de Catalunya.

Gil Estallo, M. A. (2001). «Organización vertical versus horizontal»» Conferencia en Seminario del MADOC. Granada. Septiembre, 2001.

Heintz, P. (1965). Curso de sociología. Buenos Aires: Eudeba.

Hofstede, G. (1999). Culturas y organizaciones. Madrid: Alianza.

Hunsaker, P. (1980), «Communicating Better: There's no Proxy for Proxemics», en Business, $\mathrm{n}^{\circ}$ marzo-abril, 1980: 41-48.

Jaén Díaz, M.; Luceño, L.; Martín García, J., y Rubio Valdehita, S. (2006). «La comunicación interna como herramienta estratégica en las organizaciones», en EduPsykhé, no 5. Madrid.

Kotler, P. (2000). El marketing más eficaz. Deusto: Planeta.

Krombarg (1999). Organizaciones. Madrid: McGraw Hill.

Lucas Marín, A. (2002). Sociología de la Organización. Madrid: McGraw Hill.

March, J. y Simon, H. (1958), Organizations. New York.

Perrow, C. (1994). Sociología de las organizaciones. Madrid: McGraw Hill.

Pithod, A. (2001). Comportamiento organizacional. Buenos Aires: Fundación Universidad a Distancia.

Pfeffer, P. (1999). Organizaciones. Madrid: Alianza. 
Selznick, P. (1957). Leadership in Administration. A sociological interpretation. Nueva York: Harper \& Row.

Stefanova Dimitrova, E. y Lucas Marín, A. (2006). «El concepto de cultura de las organizaciones: centralidad actual y evolución histórica», en BRUnet, I. y Alarcón, A. (2006). Sociología de la empresa y de las organizaciones. Zaragoza: Egido, págs. 291-304.

Vallejo Peña, F. A. (2007). El análisis de la cultura de una multinacional. El caso Maersk. Granada: Editorial Comares.

Weber, M. (1969). La ética protestante y el espíritu del capitalismo. Barcelona: Península. (1904; primera edición).

Wei Choo, C. (1999). La organización inteligente. Madrid: Oxford University Press. 